\title{
MULTILAYER COATINGS Ti/TiN, Cr/CrN AND W/WN DEPOSITED BY MAGNETRON SPUTTERING FOR IMPROVEMENT OF ADHESION TO BASE MATERIALS
}

\author{
J. Horník*, S. Krum, D. Tondl, M. Puchnin, P. Sachr, L. CvrČek \\ Czech Technical University in Prague, Faculty of Mechanical Engineering, Department of Materials \\ Engineering, Karlovo náměstí 13, 12135 Prague, Czech Republic \\ * corresponding author: Jakub.Hornik@fs.cvut.cz
}

ABstract. The paper deals with evaluation of single and multilayer layer PVD coatings based on $\mathrm{Cr}$ and Ti widely used in tool application. Additionally, W and WN based coating which are not so widespread were designed and deposited as functionally graded material. The coatings properties were evaluated from the point of view of hardness and adhesion. The hardness measuring was carried out using nanoindentation method. The scratch test was performed to test adhesion. Moreover, the presence of metallic interlayer in functionally graded materials further increases the coating adhesion by gradually approaching its composition to the substrate. Coatings consisting of W and WN have showed very good adhesion. With regard to the results of the scratch test, the multilayer coatings of $\mathrm{CrN}$, TiN and WN have increased adhesion and can be assumed to have their protective function improved. Results will be appliedin development of functionally graded layers for functionally graded materials.

KEYWORDS: PVD coatings; magnetron sputtering; S235 steel; adhesion; nanoindentation.

\section{INTRODUCTION}

Thin coatings are an important area of surface engineering nowadays experiencing rapid progress. Coatings have a protective or functional purpose in a wide range of technical applications. They increase substrate resistance against oxidation, heat transfer, wear and corrosion [1]. PVD (physical vapour deposition) is the one of the ways of their deposition onto tool steels substrate. The low deposition temperature is significant advantage of this method. However, these coatings show relatively low adhesion to substrate. Improvement of the adhesion may be achieved by modifying the substrate or adjusting physical properties of the coating to the substrate as much as possible in order to achieve similar mechanical properties like hardness [2]. Amongst the most used coatings, there are the PVD coatings based on $\mathrm{Cr}-\mathrm{N}$, Ti-N, Al-Ti-N, and $\mathrm{W}-\mathrm{N}$. However, tungsten or its nitrides and carbides are not widely used alternatives [3, 4] in spite of the good abrasive resistance comparable to $\mathrm{Mo}_{2} \mathrm{~N}$ with significantly lower wear loss than commercially used Ti based coatings [5]. WN based coatings suffer from rapid formation of oxides over the temperature of $500{ }^{\circ} \mathrm{C}$. These oxides occur also in surface microcracks and their growth contributes to crack propagation and coating degradation process [4]. Presented paper deals

\begin{tabular}{cc}
\hline Element & Concentration \\
\hline $\mathrm{C}$ & $\max 0.22 \mathrm{wt} \%$ \\
$\mathrm{Mn}$ & $\max 1.60 \mathrm{wt} \%$ \\
$\mathrm{P}$ & $\max 0.05 \mathrm{wt} \%$ \\
$\mathrm{~S}$ & $\max 0.05 \mathrm{wt} \%$ \\
$\mathrm{Si}$ & $\max 0.05 \mathrm{wt} \%$ \\
\hline
\end{tabular}

TABLE 1. Typical chemical composition of S 235 steel.

with characterization of PVD coatings types based on Cr, Ti and W deposited on carbon steel substrate. Selected method of scratch test [6, 7], nanoindentation [9, 10] and microscopy were used for evaluation of the coating properties. The results will be used for development of functionally graded layers for functionally graded materials.

\section{EXPERIMENT}

The Cr, Ti and $\mathrm{W}$ based coatings were selected for the experiment. As a substrate material a normalized plain carbon steel S 235 with the hardness of $185 \mathrm{HV}$ (55 HRA) was unconventionally selected. Typical composition of used steel is presented in Table 1. The reason was to better evaluate the properties of the coatings themselves.

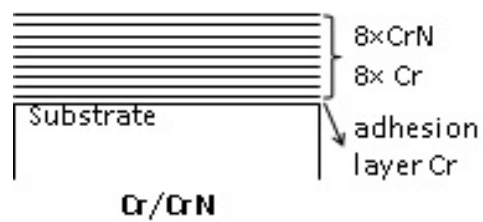

$\mathrm{Cr} / \mathrm{CrN}$

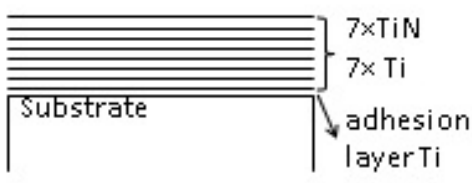

Ti/TiN

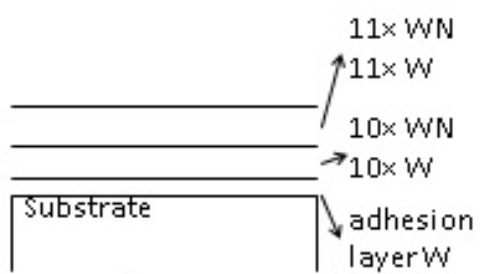

W/WN (FGM)

Figure 1. Composition of multilayer coatings. 

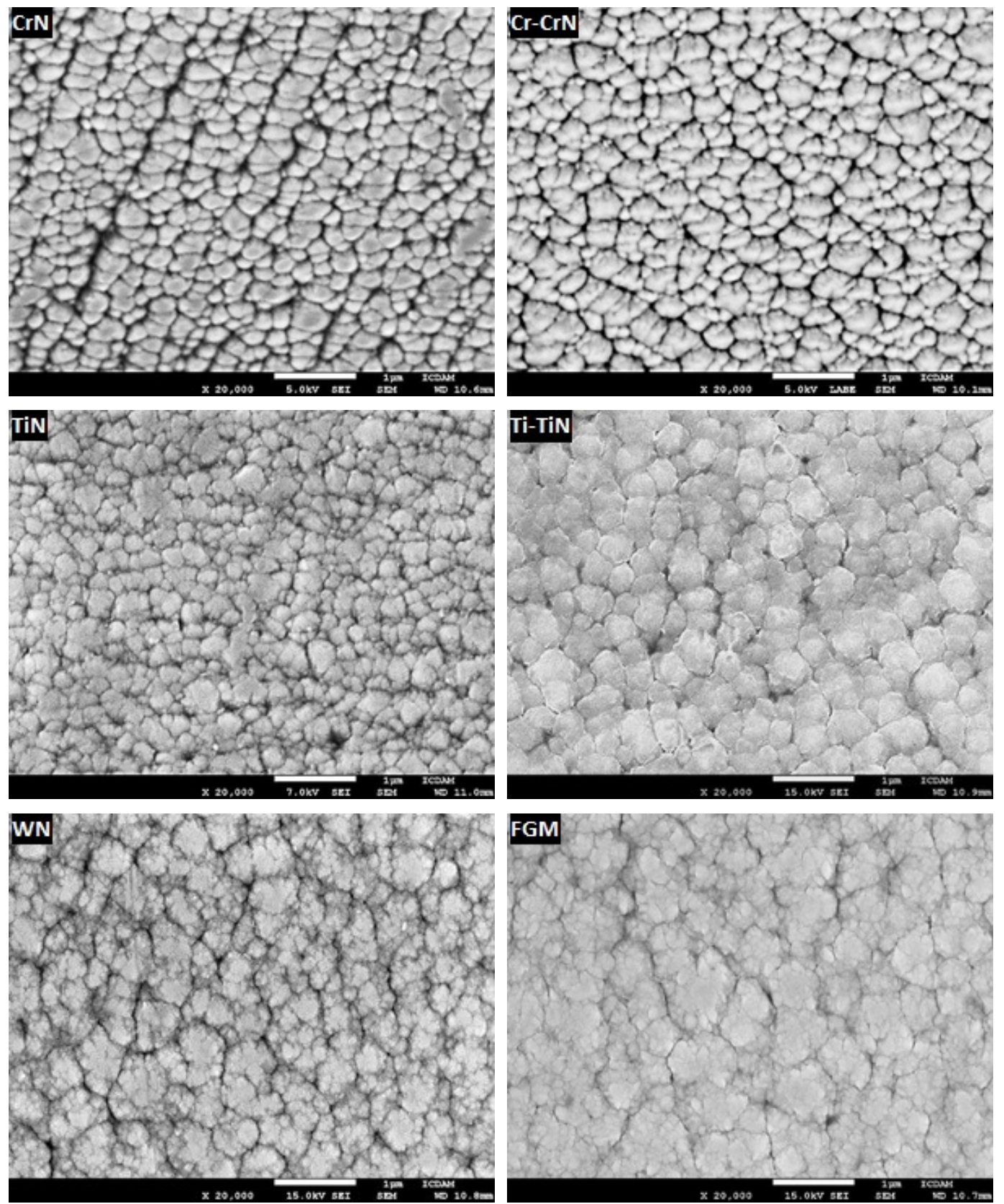

Figure 2. Surface morphology of evaluated coatings (SEM).

All samples were prepared using the deposition parameters to reach the final thickness of the coating 3-6 $1 \mathrm{~m}$. All parameters (bias voltage, coil current, gas flow etc.) were previously optimized by test cycles. Gas flows were optimized in case of FGM (functionally graded coatings) $\mathrm{W} / \mathrm{WN}$ coating (W reinforced by WN clusters) in order to reach increased hardness and sufficient adhesion. The deposition times were set to obtain approximately the same final coatings thickness for all samples. Prior to the deposition, all substrates were polished to mirror-like surface, than cleaned in an ultrasonic cleaning machine in acetone bath. The multilayers were prepared using PVD method on Hauzer Flexicoat 850 equipment. Coatings were formed as an alternating combination of pure metals and their nitrides. Adhesion layer of pure metal has thickness of $50 \mathrm{~nm}$. The composition of the prepared and tested layer systems is evident from Fig. 1 .

Adhesion measurements were performed using the CSM Revetest Xpress device with Rockwell indenter (tip angle $=120^{\circ}$, tip radius $=0.2 \mathrm{~mm}$ ). A linearly increasing load was set from 1 to $100 \mathrm{~N}$ with the loading rate of $49.5 \mathrm{~N} / \mathrm{min}$. The length of each scratch was $10 \mathrm{~mm}$. Velocity of the indenter was $5 \mathrm{~mm} / \mathrm{min}$. Micro Materials Nanotest device was used to determine the hardness of the coatings. For each sample there were made 10 indentations with the load of $200 \mathrm{mN}$ and the loading times of $10 \mathrm{sec} / 5 \mathrm{sec} / 10 \mathrm{sec}$ (load/dwell/unloading) were used. The hardness values $\mathrm{H}_{\mathrm{IT}}$ were calculated from the results of nanoindentation by Berkovich indenter. The scanning electron 

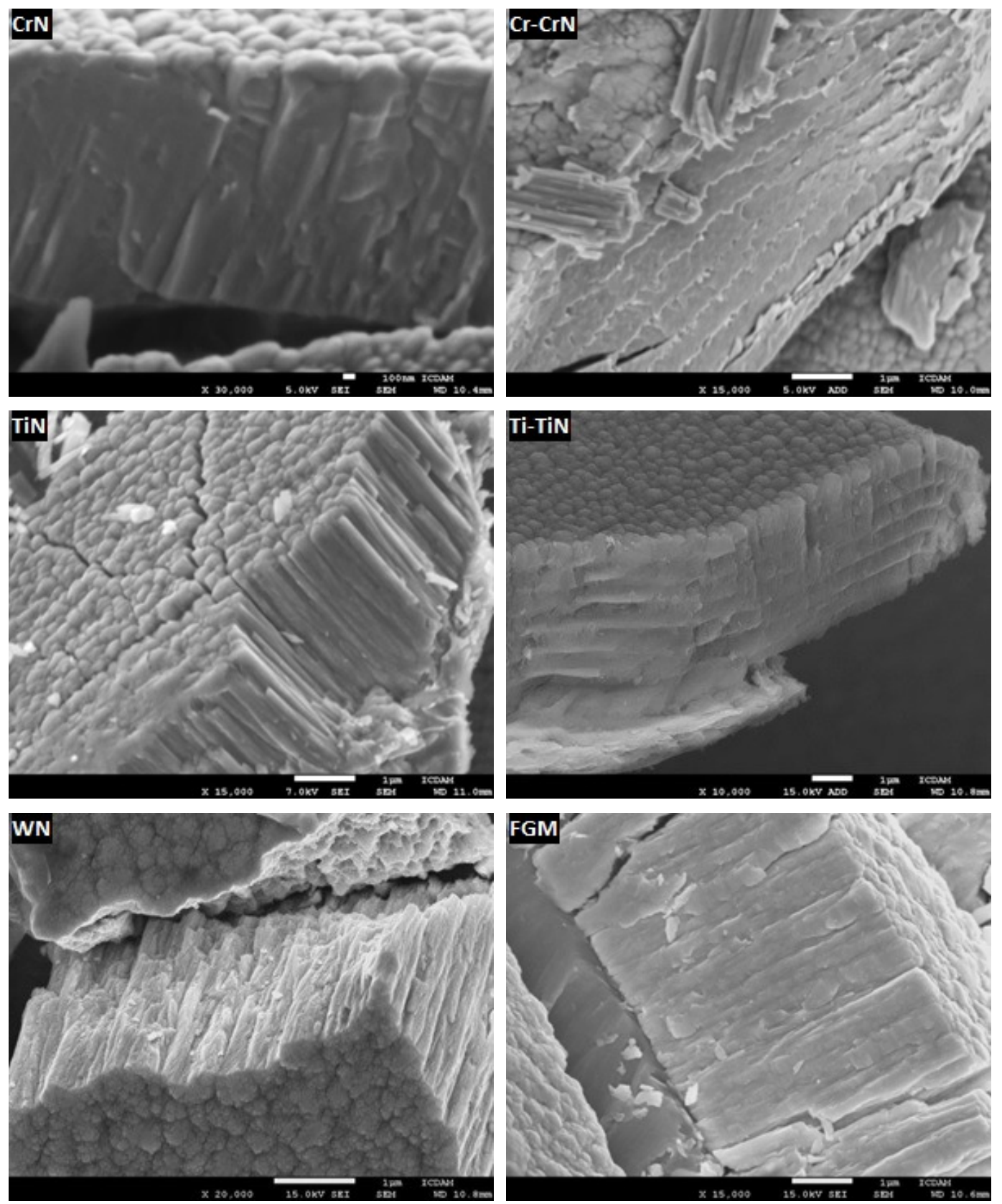

FiguRE 3. Fracture appearance and layer structure of coatings (SEM).

microscope Jeol JSM 7600F was used for the evaluation of microstructure and coating thickness.

\section{Results AND DISCUSSION}

\subsection{Microstructure}

The documentation of coatings was performed on samples after scratch test. The surface quality and tendencies to delamination were evaluated. All deposited coatings showed a columnar structure according to its growth pattern. The microphotographs in Fig. 2 show the surface morphology of the PVD coatings. Surfaces of Ti and Cr based systems have character of cupola. On surface of W/WN based PVD coating the "cauliflower" appearance dominates. Qualitatively, the surface morphology is better in case of $\mathrm{W}$ based coatings. Fracture in columnar single-layer coating structure is relatively smooth and cracks propagation is quite easier than in case of multi-layered systems (Fig. 3). The alternating of layers with different properties and their discrete interphase boundaries play a role as the decelerators against propagation of the crack.

\subsection{Mechanical properties}

Selected mechanical properties of the coatings are summarized in Tab. 2 It represents the values of nanohardness $\left(\mathrm{H}_{\mathrm{IT}}\right)$, calculated hardness $(\mathrm{HV})$ and reduced Young's modulus of elasticity $\left(E_{r}\right)$. The values of nanohardness of the $\mathrm{Cr}$ based coatings are quite low. Higher nanohardness values of TiN and W based coatings were determined. The highest hardness 


\begin{tabular}{lcccc}
\hline Coating & Nanohardness $\mathrm{H}_{\mathrm{IT}}[\mathrm{GPa}]$ & Hardness $[\mathrm{HV}]$ & $\mathrm{E}_{\mathrm{r}}[\mathrm{GPa}]$ & Coating thickness $[\mu \mathrm{m}]$ \\
\hline $\mathrm{WN}$ & 28.0 & 2855 & 258 & 3.6 \\
$\mathrm{~W} / \mathrm{WN}(\mathrm{FGM})$ & 32.2 & 3284 & 317 & 4.0 \\
\hline $\mathrm{CrN}$ & 16.2 & 1652 & 248 & 5.1 \\
$\mathrm{Cr} / \mathrm{CrN}$ (6 layers) & 18.0 & 1835 & 283 & 5.8 \\
\hline $\mathrm{TiN}$ & 24.4 & 2488 & 252 & 2.6 \\
$\mathrm{Ti} / \mathrm{TiN}$ (6 layers) & 15.5 & 1581 & 246 & 3.9 \\
\hline
\end{tabular}

TABLE 2. Mechanical properties of the coatings.

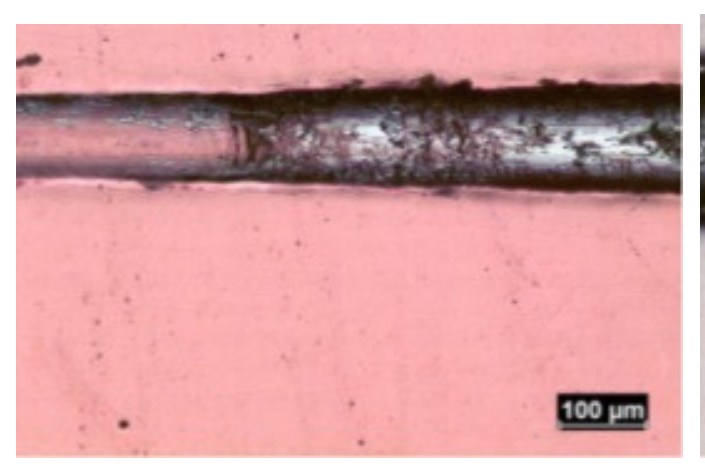

$\mathrm{TiN}-L_{c 3}, L_{S}$

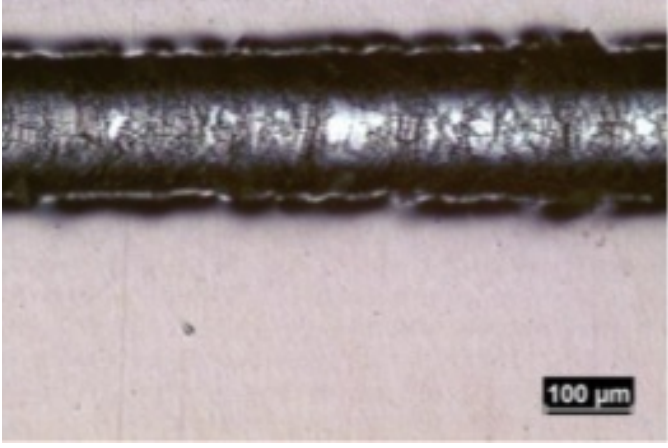

$\mathrm{W} / \mathrm{WN}(\mathrm{FGM})-L_{c 3}$

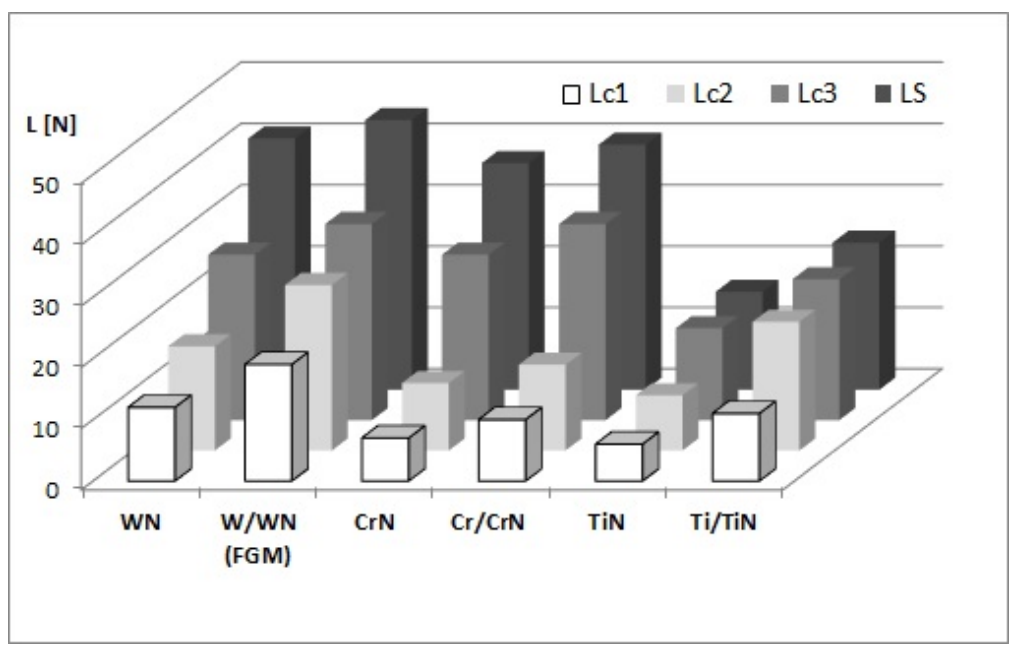

FiguRE 4. Scratches appearance on different layers and comparison of measured critical load.

was reached in case of multilayer $\mathrm{W} / \mathrm{WN}$ coating. WN coating modulus of elasticity is comparable to $\mathrm{CrN}$ and TiN. The highest value was observed in $\mathrm{W} / \mathrm{WN}$ multilayer coating. The $\mathrm{W}$ coatings are expected to be very tough. Their hardness is comparable to the common CrN coatings. The measured values of hardness and modulus of elasticity corresponds well to the available data [1, 4, 5, 10.

The most important technological parameter of coating is adhesion to the substrate. On every single residual groove (scratch) the main four characteristic are monitored: $L_{C 1}$ (the emergence of first cracks), $L_{C 2}$ (large-scale cracks), $L_{C 3}$ (first delamination of the coating) and $L_{S}$ (total coating delamination substrate exposition). The results of the scratch test of coating systems and comparison of the critical load are summarized in Tab. 3. The behaviour of all sys- tems is quite different and this fact rather complicates comparison of the results. From the Fig. 4 is evident that the multilayered coating structure improves adhesion of the system. All analyzed multilayered systems achieved better results than plain monolayers in individual criteria and overall. Highest adhesion was achieved in case of $\mathrm{W} / \mathrm{WN}$ and $\mathrm{Cr} / \mathrm{CrN}$. The combination of highest hardness, modulus of elasticity and best adhesion promotes $\mathrm{W}$ based coatings, especially the FGM type, to be very perspective for tribological application.

\section{Conclusions}

Microscopy observation reveals that all deposited coatings have homogeneous columnar structure without any cracks. Surface of $\mathrm{Cr}$ and Ti based coatings has 


\begin{tabular}{lcccc}
\hline Coating & $L_{c 1}$ & $L_{c 2}$ & $L_{c 3}$ & $L_{S}$ \\
\hline $\mathrm{WN}$ & 12 & 17 & 27 & 41 \\
$\mathrm{~W} / \mathrm{WN}$ (FGM) & 19 & 27 & 32 & 44 \\
\hline $\mathrm{CrN}$ & 7 & 11 & 27 & 37 \\
$\mathrm{Cr} / \mathrm{CrN}$ (6 layers) & 10 & 14 & 32 & 40 \\
\hline $\mathrm{TiN}$ & 6 & 9 & 15 & 16 \\
$\mathrm{Ti} / \mathrm{TiN}$ (6 layers) & 11 & 21 & 23 & 24 \\
\hline
\end{tabular}

TABLE 3. Results of scratch test (critical loads $[\mathrm{N}]$ ).

cupola character, in case of $\mathrm{W}$ based coating prevails the cauliflower appearance.

The results of scratch test showed improved adhesion in case of all multilayer coatings. Adhesion properties of the coatings deposited on soft substrate have lower values in comparison with coatings deposited on a typical tool steel but the higher penetration depth must be considered. The $\mathrm{W}$ and $\mathrm{Cr}$ based systems achieves the best adhesion results. W based coatings have very good adhesion despite to the high hardness and modulus of elasticity. The best results were achieved in case of FGM based W/WN coating in all evaluated characteristics (hardness, modulus of elasticity and adhesion).

The application of pure metals as a material of "interlayers" improves the adhesion of the coatings by gradually approaching their composition to that of the substrate.

The FGM W/WN coatings have also ambitions for use as a highly adhesive resistant coating. Obtained results will be used for further FGM research.

\section{ACKNOWLEDGEMENTS}

The research was supported by Czech Science Foundation project GAP108/12/1872 Complex functionally graded materials.

\section{REFERENCES}

[1] Grainger, S., Blunt, J. Engineering Coatings (second ed.). Woodhead Publishing LLD, Abingdon 1998 http://store.elsevier.com/Engineering-Coatings/ S-Grainger/isbn-9781845698577/

[2] Jurči, P. et al. Využití PVD povlaků na ledeburitických ocelich. Metal 2009 [CD-ROM]. Ostrava: Tanger, 2009, ISBN 978-80-87294-03-1.

[3] Hornik, J., Tondl, D., Sachr, P., Anisimov, E., Puchnin, M., Chraska, T. The Effect of PVD Tungsten-Based Coatings on Improvement of Hardness and Wear Resistance. Key Engineering Materials Vol. 606, 2014, p. $163-166$

[4] Polcar, T., Parreira, N.M.G., Cavaleiro, A. Structural and tribological characterization of tungsten nitride at elevated temperature. Wear, Vol. 265, 2008, p. 319-326

[5] Kutschej, K., Mayrhofer, P.H., Kathrein, M., Polcik, P., Tessadri, R., Mitterer, C. Structure, mechanical and tribological properties of sputtered Ti1-xAlxN coatings with $0,5<x<0,75$. Surf. Coat. Technology, Vol. 200, 2008, p. 2358-2368 doi:10.1016/j.surfcoat.2004.12.008

[6] Kadioglu et al. Crack problem for functionally graded layer on elastic foundation. International Journal of Fracture 94 (1) 1998, p.66-77 doi:10.1023/A:1007501401224

[7] Sosnová, M. Kluzné vrstvy a metody hodnocení adhezivně-kohezního a tribologického chování. [online]. Pilsen : West bohemia university in Pilsen, 2006. http://ateam.zcu.cz/FRVS_zprava_dalsi_studium_ sosnova.pdf

[8] VDI 3198, Verein Deutscher Ingenieure Normen, VDI-Verlag, Dusseldorf, 1992.

[9] EN 1071-3 Adraned technical ceramics, Determination of adhesion and mechanical failure.

[10] Oliver, W.C., Pharr, G.M. An improved technique for determining hardness and elastic modulus using load and displacement sensing indentation experiments. J. Mater. Research 7 (6), 1992, p. 1564-1583

DOI:10.1557/JMR.1992.1564 